\title{
Loss of coxsackie and adenovirus receptor expression in human colorectal cancer: A potential impact on the efficacy of adenovirus-mediated gene therapy in Chinese Han population
}

\author{
YING-YU MA ${ }^{1,2^{*}}$, XIAO-JUN WANG ${ }^{3 *}$, YONG HAN ${ }^{1,4^{*}}$, GANG LI $^{5}$, HUI-JU WANG ${ }^{1,2}$, SHI-BING WANG ${ }^{1}$, \\ XIAO-YI CHEN ${ }^{1}$, FAN-LONG LIU ${ }^{3}$, XIANG-LEI HE ${ }^{4}$, XIANG-MIN TONG ${ }^{1}$ and XIAO-ZHOU MOU ${ }^{1}$ \\ ${ }^{1}$ Clinical Research Institute; ${ }^{2}$ Key Laboratory of Gastroenterology of Zhejiang, Zhejiang Provincial People's Hospital; \\ ${ }^{3}$ Department of Anus, Rectum and Colon Surgery, First Affiliated Hospital, Zhejiang University School of Medicine; \\ ${ }^{4}$ Department of Pathology, Zhejiang Provincial People's Hospital, Hangzhou, Zhejiang 310014; \\ ${ }^{5}$ Colorectal Department of Shaoxing People's Hospital, Shaoxing Hospital of Zhejiang University, \\ Shaoxing, Zhejiang 312000, P.R. China
}

Received August 13, 2015; Accepted May 11, 2016

DOI: $10.3892 / \mathrm{mmr} .2016 .5536$

\begin{abstract}
The coxsackie and adenovirus receptor (CAR) is considered a tumor suppressor and critical factor for the efficacy of therapeutic strategies that employ the adenovirus. However, data on CAR expression levels in colorectal cancer are conflicting and its clinical relevance remains to be elucidated. Immunohistochemistry was performed on tissue microarrays containing 251 pairs of colon cancer and adjacent normal tissue samples from Chinese Han patients to assess the expression levels of CAR. Compared with healthy mucosa, decreased CAR expression (40.6\% vs. $95.6 \%$; $\mathrm{P}<0.001)$ was observed in colorectal cancer samples. The CAR immunopositivity in tumor tissues was not significantly associated with gender, age, tumor size, differentiation, TNM stage, lymph node metastasis or distant metastasis in patients with colon cancer. However, expression of CAR is present in $83.3 \%$ of the tumor tissues from patient with colorectal liver metastasis, which was significantly higher than those without liver metastasis $(39.6 \%$; $\mathrm{P}=0.042)$. At the plasma membrane, CAR was observed in $29.5 \%$ normal mucosa samples, which was significantly higher than in colorectal cancer samples $(4.0 \%$; $\mathrm{P}<0.001)$. In addition, the survival analysis demonstrated that the expression level of CAR has no association with the prognosis of colorectal cancer. CAR expression was observed to be downregulated in colorectal cancer, and it exerts complex
\end{abstract}

Correspondence to: Dr Xiao-Zhou Mou, Clinical Research Institute, Zhejiang Provincial People's Hospital, 158 Shangtang Road, Hangzhou, Zhejiang 310014, P.R. China

E-mail: mouxiaozhou@gmail.com

*Contributed equally

Key words: CAR, colorectal cancer, adenovirus-mediated gene therapy, Chinese Han population effects during colorectal carcinogenesis, potentially depending on the stage of the cancer development and progression. High CAR expression may promote liver metastasis. With regard to oncolytic therapy, CAR expression analysis should be performed prior to adenoviral oncolytic treatment to stratify Chinese Han patients for treatment.

\section{Introduction}

Colorectal cancer (CRC) is the third most commonly diagnosed cancer and the second leading cause of cancer-associated mortality in the United States (1). In China, colorectal cancer has become the second and fourth leading cause of cancer-associated mortality in women and men, respectively (2). Despite recent progress, novel therapeutic agents are required in intestinal oncology (3). Previously, gene therapy has been proposed as a potential novel treatment strategy for colorectal cancer, preclinical data using adenovirus vectors has been promising and a number of clinical trials utilizing this vector are underway $(4,5)$. The safety of adenovirus vectors have been established by various phase I trials, however, the factors determining the efficiency of gene delivery remain to be elucidated.

The coxsackie and adenovirus receptor (CAR), a transmembrane component of the tight junction complex, was initially identified as a viral attachment site on the surface of epithelial cells, which was required for subsequent virus uptake $(6,7)$. Walters et al (8) demonstrated that CAR is key in gene transfer efficacy and functions as a primary receptor for the coxsackie B virus and adenovirus. Pandha et al (9) determined that CAR levels are closely associated with adenovirus attachment, infection and transgene expression. Attenuated adenoviruses, which may be replication-incompetent to deliver therapeutic genes or viruses replicating only in certain cell types, may be used as a cancer therapy (10). Thus, the presence of CAR is considered an important determinant for the efficacy of therapeutic strategies using adenoviruses. 
Analysis of CAR expression in different types of tumor demonstrated varied results. Accumulating evidence indicates that CAR expression levels are low in a number of types of tumor, including ovarian, lung, breast and bladder (11-14), particularly in those tumors exhibiting poor differentiation and advanced disease stage $(12,15,16)$. In addition, downregulated expression of CAR predicted a poor clinical outcome for gastric and bladder cancer patients $(12,17)$. By contrast, CAR upregulation was also observed in cancer of the endometrium, ovary, cervix, breast and lung, as well as neuroblastomas and medulloblastomas (18-24). Furthermore, high CAR expression has been associated with poor prognosis in breast and lung cancer $(15,20)$. It remains to be elucidated whether these results reflect differences in CAR expression levels or are a result of racial and methodological differences.

In CRC, Zhang et al (25) observed a high variability in CAR expression levels with $\sim 75 \%$ of the cases demonstrating CAR downregulation. Reeh et al (26) also demonstrated that CAR expression levels were decreased in CRC. However, Stecker et al (27) indicated that CAR facilitates complex effects during colorectal carcinogenesis, potentially mediated by its stage-dependent subcellular distribution, and loss of CAR expression promotes growth and metastasis of primary CRC (27). These results suggested CAR has a complex role in carcinogenesis. However, to the best of our knowledge, no research has focused on the association between CAR expression levels and clinicopathological features of CRC. In our previous study, an oncolytic adenovirus was developed by inserting a CRC-specific suppressor gene, ST13, into a CRC-specific oncolytic virus. This virus exhibited marked antitumor effects, which inhibited tumor growth in CRC xenografts (28). However, as a key determinant of the efficacy of gene transfer, the clinical relevance of CAR expression in CRC requires further determination.

In the present study, immunohistochemistry was conducted to assess CAR expression in CRC and adjacent normal tissue samples in a tissue microarrays (TMA). Large sample sizes were selected to generate data allowing increased understanding the role of CAR in the pathological progress of CRC. In addition, potential targets for adenovirus-mediated therapies based on CAR expression may also be identified.

\section{Materials and methods}

CRC patients in tissue microarray. The CAR protein expression levels were assessed with immunohistochemical staining of tissue microarrays, which were purchased from Shanghai Biochip Co., Ltd. (Shanghai, China). The TMAs containing a total of 502 formalin-fixed, paraffin-embedded archival samples from a total of 251 CRC patients from the Chinese Han population, in addition to 251 corresponding controls derived from adjacent normal tissue samples.

The patient cohort consisted of 139 males and 112 females, with a median age of 66 years (range, 27-91 years) at the time of surgery. All patients had follow-up records for $>5$ years. The survival time was calculated from the date of surgery to the follow-up deadline or mortality.

Immunohistochemistry analysis. TMA sections were used for subsequent immunohistochemical analysis. Briefly, TMA sections were deparaffinized and dehydrated employing standard procedures using xylene and graded alcohol. Antigen retrieval was conducted by autoclaving in $0.01 \mathrm{M}$ citrate buffer (pH 6.0) for $3 \mathrm{~min}$. The sections were then treated with $3 \%$ hydrogen peroxide to quench endogenous peroxidase activity, and incubated with $10 \%$ normal goat serum to reduce background non-specific binding. TMA sections were incubated with a rabbit anti-human primary polyclonal antibody against CAR (dilution, 1:50; Santa Cruz Biotechnology, Inc., Dallas, TX, USA; cat. no. sc-15405) overnight at $4^{\circ} \mathrm{C}$. PBS used in place of the primary antibody served as a negative control. Subsequently, a biotinylated goat anti-rabbit immunoglobulin (Histostain-Plus IHC kit; Invitrogen; Thermo Fisher Scientific, Inc., Waltham, MA, USA) was used as a secondary antibody, followed by treatment with streptavidin-biotinylated horseradish peroxidase complex (Invitrogen; Thermo Fisher Scientific, Inc.). The slides were stained with 3,3-diaminobenzidine and counterstained with hematoxylin, dehydrated in a graded alcohol series and mounted.

Evaluation of immunohistochemical staining. Immunohistochemical staining for CAR was observed predominantly in the membrane and cytoplasm of tumor cells. The degree of immunostaining was reviewed under light microscopy by two expert pathologists who were blinded to the clinical data and scored independently. Immunopositivity at the plasma membrane was also assessed separately. The CAR expression level was determined using the intensity of staining and percentage of immunoreactive cancer cells. Staining intensity was graded as follows: 0 , no staining; 1 , weak staining; 2 , moderate staining; and 3 , strong staining. Staining percentage was graded according to the proportion of positively stained tumor cells as follows: $0,<5 \%$ positive tumor cells; $1,6-25 \%$ positive tumor cells; 2 , $26-50 \%$ positive tumor cells; and $3,>51 \%$ positive tumor cells. The immunoreactive score was calculated by percentage of positive cells multiplied by staining intensity score. For further evaluation, a staining index score of $\leq 3$ was used to define tumors with CAR-negative, and a tumor with a staining index score of $\geq 4$ was regarded as CAR-positive.

Genomic analysis. Gene-therapeutic agent interaction data was downloaded from the Comparative Toxicogenomics Database (CTD; ctdbase.org). R 3.2.1 (R Foundation for Statistical Computing; www.r-project.org) was utilized to perform the analyses.

Statistical analysis. All statistical analyses were performed using SPSS 13.0 (SPSS Inc., Chicago, IL, USA). Categorical data were analyzed using the $\chi^{2}$ or Fisher's exact test to assess the association between the expression of CAR and the clinicopathological parameters of patients with colon cancer. The Kaplan-Meier method was performed to estimate survival curves, accompanying the log-rank test to calculate differences between the curves. Cox proportional hazards regression model was used to perform multivariate survival analysis to assess predictors associated with prognosis. In addition, correlation between CAR protein expression levels and clinicopathological features were estimated using the Spearman correlation method. All P-values were two-sided and $\mathrm{P}<0.05$ was considered to indicate a statistically significant difference. 


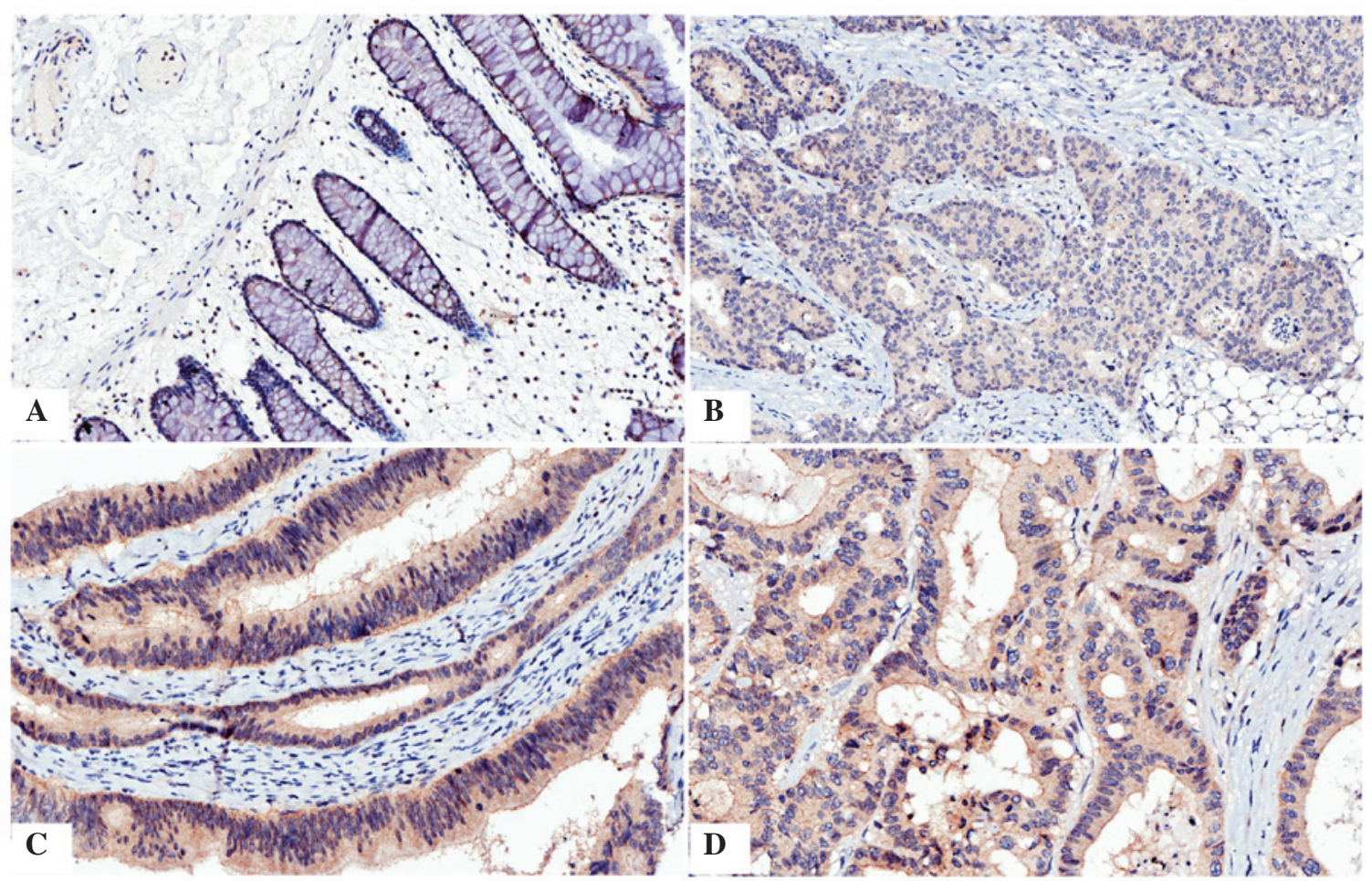

Figure 1. Immunohistochemical analysis of CAR in colon cancer and normal tissue. (A) Immunostaining of CAR in normal colon tissue, positive staining was observed in the cytoplasm and, predominantly, the membrane. (B) Immunostaining of CAR in poorly differentiated colon cancer, positive staining was predominantly observed in the cytoplasm. (C) Immunostaining of CAR in moderately differentiated colon cancer, positive staining was observed in the membrane and, predominantly, the cytoplasm. (D) Immunostaining of CAR in colon cancer with liver matastasis, positive staining was observed in the cytoplasm and membrane. Magnification, x400. CAR, coxsackie and adenovirus receptor.

\section{Results}

Expression of CAR in CRC samples was lower than in corresponding normal tissue samples. Immunohistochemistry was used to analyze the presence and distribution of CAR. It was observed that immunostaining of CAR was predominantly located in the membrane and cytoplasm of the cells (Fig. 1). Positive expression of CAR protein was detected in 240 of 251 (95.6\%) noncancerous colorectal mucosa samples, which was significantly higher than in CRC $\left(40.6 \%, 102 / 251, \chi^{2}=174.7\right.$, $\mathrm{P}<0.001$; detailed data not shown).

CAR immunopositivity is associated with metastasis in $C R C$. In order to investigate whether the presence of CAR is associated with the development of CRC, the CAR expression was compared with clinicopathological parameters of CRC. The results demonstrated that the prevalence of cytoplasmic CAR immunopositivity was not significantly associated with gender, age, tumor size, differentiation, TNM stage, lymph node metastasis or distant metastasis (Table I). However, CAR immunopositivity was detected in $83.3 \%$ (5/6) of patients with colorectal liver metastasis, which was significantly higher than those without liver metastasis $(39.6 \%, 97 / 245, \mathrm{P}=0.042)$.

Survival analysis indicates CAR immunopositivity does not significantly decrease survival time. The mean survival time in colon cancer patients with CAR immunopositivity was $61.50 \pm 3.31$ months, which demonstrated no significant difference between survival time compared with CAR-negative patients $(58.96 \pm 2.87$ months, $\mathrm{P}=0.654)$. The Kaplan-Meier survival curve also demonstrated that CAR expression had no significant association with overall survival (Fig. 2). In addition, factors with possible prognostic effects in colon cancer were analyzed by Cox regression analysis, and the results indicated that distant metastasis was an independent prognostic factors in patients with $\mathrm{CRC}(\mathrm{P}=0.001)$, while $\mathrm{CAR}$ expression was not $(\mathrm{P}=0.355$; Table II).

Plasma membrane expression of CAR in CRC was decreased compared with normal mucosal samples. CAR is a transmembrane glycoprotein, which is a viral attachment site on the surface of epithelial cells. CAR expression in the plasma membrane is important role in virus uptake. Thus, the present study analyzed the presence of CAR in the plasma membrane. CAR was observed at the plasma membrane of normal mucosa samples $(29.5 \%, 74 / 251)$, which was indicated to be significantly higher than in CRC samples $(4.0 \%, 10 / 251, \mathrm{P}<0.001)$. However, further analysis demonstrated that none of the clinicopathological parameters were significantly associated with the plasma membrane expression of CAR in primary CRC (data not shown).

Certain therapeutic agents may upregulate CAR expression levels. The CTD database was searched for therapeutic agents and chemicals that may upregulate the mRNA or protein expression levels of CAR, based on their applications in cancer management. The results indicated that a number of therapeutic agents, including PJ-34, dietary fats, calcitriol, testosterone, gentamicins and torcetrapib may upregulate the expression of CAR. 
Table I. Association between CAR expression and clinicopathological features of colon cancer.

\begin{tabular}{|c|c|c|c|c|}
\hline \multirow[b]{2}{*}{ Clinical parameters } & \multicolumn{4}{|c|}{ CAR expression } \\
\hline & Negative (\%) & Positive (\%) & $\chi^{2}$ & P-value \\
\hline Gender & & & 0.148 & 0.701 \\
\hline Male & $84(60.4)$ & $55(39.6)$ & & \\
\hline Female & $65(58.0)$ & $47(42.0)$ & & \\
\hline Age (yrs) & & & 0.4595 & 0.441 \\
\hline$<60$ & $40(63.5)$ & $23(36.5)$ & & \\
\hline$\geq 60$ & $109(58.0)$ & $79(42.0)$ & & \\
\hline Tumor diameter & & & 1.151 & 0.283 \\
\hline$<20 \mathrm{~cm}$ & $76(62.8)$ & $45(37.2)$ & & \\
\hline$\geq 20 \mathrm{~cm}$ & $73(56.2)$ & $57(43.8)$ & & \\
\hline Differentiation & & & 2.943 & 0.230 \\
\hline High & $28(56.0)$ & $22(44.0)$ & & \\
\hline Moderate & $86(57.0)$ & $65(43.0)$ & & \\
\hline Poor & $35(70.0)$ & $15(30.0)$ & & \\
\hline TNM stage & & & 0.053 & 0.818 \\
\hline TNM I+II & $84(58.7)$ & $59(41.3)$ & & \\
\hline TNM III+IV & $65(60.2)$ & $43(39.8)$ & & \\
\hline Lymph node metastasis & & & 0.636 & 0.425 \\
\hline No & $86(57.3)$ & $64(42.7)$ & & \\
\hline Yes & $63(62.4)$ & $38(37.6)$ & & \\
\hline Distant metastasis & & & 2.675 & 0.164 \\
\hline No & $146(60.6)$ & $96(39.7)$ & & \\
\hline Yes & $3(33.3)$ & $6(66.7)$ & & \\
\hline Liver metastasis & & & 4.645 & 0.042 \\
\hline Negative & $148(60.4)$ & 97 (39.6) & & \\
\hline Positive & $1(16.7)$ & $5(83.3)$ & & \\
\hline
\end{tabular}

CAR, coxsackie and adenovirus receptor.

Table II. Cox-regression analysis of the clinicopathological parameters in colon cancer patients.

\begin{tabular}{|c|c|c|c|c|}
\hline Parameters & Coefficient & $\mathrm{HR}$ & $95.0 \% \mathrm{CI}$ for $\mathrm{HR}$ & $\mathrm{P}$ \\
\hline Gender & 0.321 & 1.116 & $0.748-1.667$ & 0.590 \\
\hline Age & 0.110 & 1.379 & $0.848-2.243$ & 0.195 \\
\hline Distant metastasis & 0.328 & 5.474 & $1.947-15.386$ & 0.001 \\
\hline Tumor diameter & 0.299 & 1.388 & $0.929-2.076$ & 0.110 \\
\hline Lymph node metastasis & 0.424 & 1.528 & $0.497-4.701$ & 0.460 \\
\hline TNM stage & 0.258 & 1.295 & $0.397-4.223$ & 0.668 \\
\hline Differentiation & 1.700 & 1.348 & $0.986-1.843$ & 0.061 \\
\hline CAR expression & -0.192 & 0.826 & $0.550-1.239$ & 0.355 \\
\hline
\end{tabular}

HR, hazard ratio; CAR, coxsackie and adenovirus receptor; CI, confidence interval.

\section{Discussion}

In the present study of the Chinese Han population, high CAR expression levels was observed in normal colorectal tissues, which is consistent with previous studies $(12,27,29)$.
A decrease in CAR expression in primary CRC samples was also observed, with $40.6 \%$ positive detection rate. These data suggest that reduced CAR expression contributes to carcinogenesis and progression of primary CRC. Furthermore, low CAR protein expression in CRC may result in poor adenoviral 


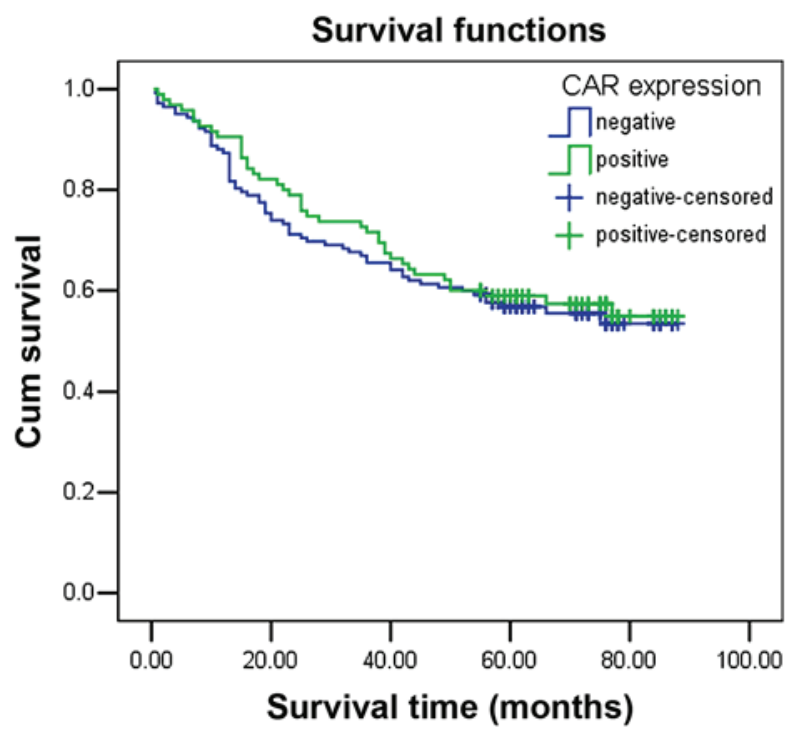

Figure 2. Kaplan-Meier survival curve analysis in patients with positive and negative CAR expression demonstrating CAR expression has no significant association with overall survival. CAR, coxsackie and adenovirus receptor.

transduction efficiency. In order to assess the profile of CAR in the development of CRC, the association between CAR expression and clinicopathological features of CRC was analyzed. CAR immunopositivity was not significantly associated with age, gender or any other clinicopathological feathers, which was consistent with previous observations by Stecker et al (27). However, CAR immunopositivity was significantly associated with liver metastasis. Korn et al (29) reported that $60 \%$ of cases of CRC with metastases in the liver exhibited CAR expression. Rauen et al (30) also demonstrated that CAR immunopositivity was significantly higher in prostate cancer with metastasis than in primary cancer. However, as the number of examined patients with liver metastases in the present study is small, the current study hypothesizes that CAR may exert a complex effect on the process of colon cancer development, potentially depending on its stage in Chinese Han population, and further studies are required to confirm the result.

CRC may be surgically treated with chemoradiotherapy as a adjuvant therapy. However, the outcome is not ideal, and liver metastasis may result in post-operative relapse (31). Cady and Stone (32) indicated that $20-40 \%$ of patients had liver metastasis when first diagnosed, however, the incidence of liver metastasis following radical resection of CRC was 40-50\%. Furthermore, liver metastasis occurred in $>50 \%$ of CRC-associated mortality. Tomlinson et al (33) reported that Liver-directed therapy in colorectal liver metastasis in addition to rational implementation of chemotherapeutic regimens have resulted in median survival time of $>30$ months and the potential for cure with resection. The present study demonstrated that CAR immunopositivity was significantly upregulated in patients with liver metastasis, which suggest that high CAR expression may support the establishment of metastasis, particularly in liver metastasis. Thus, the present study hypothesizes that CAR may be used for monitoring and/or predicting the outcome of adenovirus-mediated gene therapy, particularly to improve the efficacy of therapeutic strategies using adenoviruses in CRC with liver metastasis. 
There are few studies that aimed to determine the value of CAR expression in the prognosis of cancer. Thus, the present study aimed to investigate the clinical importance of CAR expression in the prognosis of patients with CRC. It was observed that survival time in patients with moderate or strong tumor CAR expression was longer than those with low expression, however, this was not a statistically significant difference when analyzed using univariate analysis. Martin et al (20) indicated that elevated levels of CAR expression were markedly associated with poor overall survival in patients with breast cancer. It had also been previously demonstrated that the soluble splice variants CAR 3/7 and CAR 4/7, but not the full-length human CAR were independent prognostic factors in progression-free and overall survival of patients with ovarian cancer (23). These results suggest that in addition to its important role in coxsackie and adenovirus cell-entry, CAR is also involved in cell-cell adhesions, exerting effects of a cell surface receptor and resulting in different characteristics depending on the tumor type, and the prognostic value of CAR in CRC remains to be determined by investigating larger sample sizes and adjusting for other relative factors.

Considering the reduced expression of CAR, a number of adenovirus targeting strategies that aim to improve the efficacy of adenovirus-mediated gene therapy in CRC. Structural alteration of adenovirus vectors or drug-induced CAR expression has become a focus of research in the field of adenovirus-mediated therapy. For example, chemical modification of the adenovirus capsid or fiber alteration (swapping and replacement) may promote CAR-independent gene transfer efficiency (34-36). The fiber-swapping of adenovirus type 5 (Ad5) fibers with subgroup B adenovirus fibers, such as Ad3, Ad35, or Ad11, results in vectors with CAR-independent transduction, mediated via the group B Ad receptors, including cluster of differentiation (CD)46, CD80/CD86, or 'receptor X' (37-39). In addition, it has been demonstrated that the trimerization function of the fiber knob may be replaced by the fold on domain from the bacteriophage T4 fibritin protein (40) or extrinsic trimerization motifs, such as the MoMuLV envelope glycoprotein trimerization domain (41).

Previous studies (as presented in Table III) have demonstrated that a variety of therapeutic agents enhance the efficacy of adenovirus-mediated gene transduction via elevating CAR expression in target cells. Trichostatin A induced the expression of CAR in esophageal squamous cell carcinoma cell lines via the mitogen-activated protein kinase/extracellular-regulated kinase $1 / 2$ signaling pathway (42). Treatment of cells with the histone deacetylase inhibitor, FR901228 (a depsipeptide) increased CAR RNA levels in cancer cell lines, including carcinoma of the thyroid, colon, renal cell, breast and hepatic cell, and it is associated with enhanced adenoviral transgene expression following infection (43). Yoo et al (44) also demonstrated that docetaxel enhanced $\mathrm{p} 53$ transduction using an adenovirus by increasing CAR expression. In addition, interaction network analysis was performed using the CTD, and CAR was searched in the CTD database for therapeutic agents and chemicals that may upregulate the mRNA or protein expression levels of CAR, and these were selected based on their applications in cancer management. The result demonstrated that a number of therapeutic agents, such as PJ-34 may upregulate the expression of CAR, which is crucial for the efficacy of the treatment of adenovirus-mediated gene therapy in CRC.

The results of the present study suggest that CAR facilitates complex effects during CRC carcinogenesis in the Chinese Han population, potentially depending on the stage of the cancer development and progression. In addition, the current study indicated various therapeutic agents that may increase the expression of CAR in order to improve adenovirus-mediated gene therapy efficacy in CRC.

In conclusion, CAR expression has potential as a marker for monitoring and/or predicting the outcome of gene therapy, and increasing its expression levels may contribute to the upregulation of cellular sensitivity towards adenovirus infection.

\section{Acknowledgements}

The present study was supported by the National Natural Science Foundation of China (grant nos. 81201783, 81372463 and 81472210), the Zhejiang Provincial Natural Science Foundation of China (grant nos. LY15H160051, LY14H160041 and LY13H080005), the Funds of Science Technology Department of Zhejiang Province (grant no. 2014C37101), the Zhejiang Province Bureau of Health (grant no. 2015ZA009), and the Open Fund of Zhejiang Provincial Top Key Discipline of Biology.

\section{References}

1. Siegel R, Naishadham D and Jemal A: Cancer statistics, 2013. CA Cancer J Clin 63: 11-30, 2013.

2. Chen W, Zheng R, Zhang S, Zhao P, Li G, Wu L and He J: Report of incidence and mortality in China cancer registries, 2009. Chin J Cancer Res 25: 10-21, 2013.

3. Chang GJ, Kaiser AM, Mills S, Rafferty JF and Buie WD; Standards Practice Task Force of the American Society of Colon and Rectal Surgeons: Practice parameters for the management of colon cancer. Dis Colon Rectum 55: 831-843, 2012.

4. Rayburn ER, Wang W, Zhang R and Wang H: Experimental therapy for colon cancer: Anti-cancer effects of TLR9 agonism, combination with other therapeutic modalities, and dependence upon p53. Int J Oncol 30: 1511-1519, 2007.

5. Zuckerman DS and Clark JW: Systemic therapy for metastatic colorectal cancer: Current questions. Cancer 112: 1879-1891, 2008.

6. Bergelson JM, Cunningham JA, Droguett G, Kurt-Jones EA, Krithivas A, Hong JS, Horwitz MS, Crowell RL and Finberg RW: Isolation of a common receptor for Coxsackie B viruses and adenoviruses 2 and 5. Science 275: 1320-1333, 1997.

7. Cohen CJ, Shieh JT, Pickles RJ, Okegawa T, Hsieh JT and Bergelson JM: The coxsackievirus and adenovirus receptor is a transmembrane component of the tight junction. Proc Natl Acad Sci USA 98: 15191-15196, 2001.

8. Walters RW, Freimuth P, Moninger TO, Ganske I, Zabner J and Welsh MJ: Adenovirus fiber disrupts CAR-mediated intercellular adhesion allowing virus escape. Cell 110: 789-799, 2002.

9. Pandha HS, Stockwin LH, Eaton J, Clarke IA, Dalgleish AG, Todryk SM and Blair GE: Coxsackie B and adenovirus receptor, integrin and major histocompatibility complex class I expression in human prostate cancer cell lines: Implications for gene therapy strategies. Prostate Cancer Prostatic Dis 6: 6-11, 2003.

10. Kasuya H, Takeda S, Shimoyama S, Shikano T, Nomura N, Kanazumi N, Nomoto S, Sugimoto H and Nakao A: Oncolytic virus therapy-foreword. Curr Cancer Drug Targets 7: 123-125, 2007.

11. Abdolazimi Y, Mojarrad M, Pedram M and Modarressi MH: Analysis of the expression of coxsackievirus and adenovirus receptor in five colon cancer cell lines. World J Gastroenterol 13: 6365-6369, 2007. 
12. Anders M, Vieth M, Röcken C, Ebert M, Pross M, Gretschel S, Schlag PM, Wiedenmann B, Kemmner W and Höcker M: Loss of the coxsackie and adenovirus receptor contributes to gastric cancer progression. Br J Cancer 100: 352-359, 2009.

13. Wang Y, Thorne S, Hannock J, Francis J, Au T, Reid T, Lemoine N, Kirn D and Halldén G: A novel assay to assess primary human cancer infectibility by replication-selective oncolytic adenoviruses. Clin Cancer Res 11: 351-360, 2005.

14. Yamashita M, Ino A, Kawabata K, Sakurai F and Mizuguchi $H$ : Expression of coxsackie and adenovirus receptor reduces the lung metastatic potential of murine tumor cells. Int J Cancer 121: 1690-1696, 2007.

15. Wunder T, Schmid K, Wicklein D, Groitl P, Dobner T, Lange T, Anders M and Schumacher U: Expression of the coxsackie adenovirus receptor in neuroendocrine lung cancers and its implications for oncolytic adenoviral infection. Cancer Gene Ther 20: 25-32, 2013.

16. Wunder T, Schumacher U and Friedrich RE: Coxsackie adenovirus receptor expression in carcinomas of the head and neck. Anticancer Res 32: 1057-1062, 2012.

17. Matsumoto K, Shariat SF, Ayala GE, Rauen KA and Lerner SP Loss of coxsackie and adenovirus receptor expression is associated with features of aggressive bladder cancer. Urology 66 : 441-446, 2005

18. Dietel M,Häfner N, Jansen L, Durst M and Runnebaum IB: Novel splice variant CAR $4 / 6$ of the coxsackie adenovirus receptor is differentially expressed in cervical carcinogenesis. J Mol Med (Berl) 89: 621-630, 2011.

19. Giaginis CT, Zarros AC, Papaefthymiou MA, Papadopouli AE, Sfiniadakis IK and Theocharis SE: Coxsackievirus and adenovirus receptor expression in human endometrial adenocarcinoma: Possible clinical implications. World J Surg Oncol 6: 59, 2008.

20. Martin TA, Watkins G and Jiang WG: The Coxsackie-adenovirus receptor has elevated expression in human breast cancer. Clin Exp Med 5: 122-128, 2005.

21. Martino TA, Petric M, Weingartl H, Bergelson JM, Opavsky MA, Richardson CD, Modlin JF, Finberg RW, Kain KC, Willis N, et al: The coxsackie-adenovirus receptor (CAR) is used by reference strains and clinical isolates representing all six serotypes of coxsackievirus group B and by swine vesicular disease virus. Virology 271: 99-108, 2000.

22. Persson A, Fan X, Widegren B and Englund E: Cell type- and region-dependent coxsackie adenovirus receptor expression in the central nervous system. J Neurooncol 78: 1-6, 2006

23. Reimer D, Steppan I, Wiedemair A, Concin N, Hofstetter G, Marth C, Müller-Holzner E and Zeimet AG: Soluble isoforms but not the transmembrane form of coxsackie-adenovirus receptor are of clinical relevance in epithelial ovarian cancer. Int J Cancer 120: 2568-2575, 2007.

24. Wang Y, Wang S, Bao Y, Ni C, Guan N, Zhao J, Salford LG, Widegren $\mathrm{B}$ and Fan X: Coxsackievirus and adenovirus receptor expression in non-malignant lung tissues and clinical lung cancers. J Mol Histol 37: 153-160, 2006.

25. Zhang NH, Song LB, Wu XJ, Li RP, Zeng MS, Zhu XF, Wan DS Liu Q, Zeng YX and Zhang XS: Proteasome inhibitor MG-132 modifies coxsackie and adenovirus receptor expression in colon cancer cell line lovo. Cell Cycle 7: 925-933, 2008

26. Reeh M, Bockhorn M, Görgens D, Vieth M, Hoffmann T, Simon R, Izbicki JR, Sauter G, Schumacher U and Anders M: Presence of the coxsackievirus and adenovirus receptor (CAR) in human neoplasms: A multitumour array analysis. Br J Cancer 109: 1848-1858, 2013.

27. Stecker K, Vieth M, Koschel A, Wiedenmann B, Röcken C and Anders $\mathrm{M}$ : Impact of the coxsackievirus and adenovirus receptor on the adenoma-carcinoma sequence of colon cancer. Br J Cancer 104: 1426-1433, 2011.
28. Zhou X, Xie G, Wang S, Wang Y, Zhang K, Zheng S, Chu L, Xiao L, Yu Y, Zhang Y and Liu X: Potent and specific antitumor effect for colorectal cancer by CEA and Rb double regulated oncolytic adenovirus harboring ST13 gene. PLoS One 7: e47566, 2012.

29. Korn WM, Macal M, Christian C, Lacher MD, McMillan A, Rauen KA, Warren RS and Ferrell L: Expression of the coxsackievirus- and adenovirus receptor in gastrointestinal cancer correlates with tumor differentiation. Cancer Gene Ther 13: 792-797, 2006.

30. Rauen KA, Sudilovsky D, Le JL, Chew KL, Hann B, Weinberg V, Schmitt LD and McCormick F: Expression of the coxsackie adenovirus receptor in normal prostate and in primary and metastatic prostate carcinoma: Potential relevance to gene therapy. Cancer Res 62: 3812-3818, 2002.

31. van Gijn W, Krijnen P, Lemmens VE, den Dulk M, Putter H and van de Velde CJ: Quality assurance in rectal cancer treatment in the Netherlands: A catch up compared to colon cancer treatment. Eur J Surg Oncol 36: 340-344, 2010.

32. Cady B and Stone MD: The role of surgical resection of liver metastases in colorectal carcinoma. Semin Oncol 18: 399-406, 1991.

33. Tomlinson JS, Jarnagin WR, DeMatteo RP, Fong Y, Kornprat P, Gonen M, Kemeny N, Brennan MF, Blumgart LH and D'Angelica M: Actual 10-year survival after resection of colorectal liver metastases defines cure. J Clin Oncol 25: 4575-4580, 2007.

34. Fisher KD, Stallwood Y, Green NK, Ulbrich K, Mautner V and Seymour LW: Polymer-coated adenovirus permits efficient retargeting and evades neutralising antibodies. Gene Ther 8: 341-348, 2001 .

35. Lanciotti J, Song A, Doukas J, Sosnowski B, Pierce G, Gregory R, Wadsworth S and O'Riordan C: Targeting adenoviral vectors using heterofunctional polyethylene glycol FGF2 conjugates. Mol Ther 8: 99-107, 2003.

36. Menezes KM, Mok HS and Barry MA: Increased transduction of skeletal muscle cells by fibroblast growth factor-modified adenoviral vectors. Hum Gene Ther 17: 314-320, 2006.

37. Segerman A, Atkinson JP, Marttila M, Dennerquist V, Wadell G and Arnberg N: Adenovirus type 11 uses CD46 as a cellular receptor. J Virol 77: 9183-9191, 2003.

38. Short JJ, Pereboev AV, Kawakami Y, Vasu C, Holterman MJ and Curiel DT: Adenovirus serotype 3 utilizes CD80 (B7.1) and CD86 (B7.2) as cellular attachment receptors. Virology 322: 349-359, 2004

39. Tuve S, Wang H, Ware C, Liu Y, Gaggar A, Bernt K, Shayakhmetov D, Li Z, Strauss R, Stone D and Lieber A: A new group $\mathrm{B}$ adenovirus receptor is expressed at high levels on human stem and tumor cells. J Virol 80: 12109-12120, 2006.

40. Krasnykh V, Belousova N, Korokhov N, Mikheeva G and Curiel DT: Genetic targeting of an adenovirus vector via replacement of the fiber protein with the phage T4 fibritin. J Virol 75: 4176-4183, 2001.

41. van Beusechem VW, van Rijswijk AL, van Es HH, Haisma HJ, Pinedo HM and Gerritsen WR: Recombinant adenovirus vectors with knobless fibers for targeted gene transfer. Gene Ther 7 : $1940-641,2000$.

42. Ma J, Zhao J, Lu J, Jiang Y, Yang H, Li P, Zhao M, Liu K and Dong Z: Coxsackievirus and adenovirus receptor promotes antitumor activity of oncolytic adenovirus H101 in esophageal cancer. Int J Mol Med 30: 1403-1409, 2012.

43. Kitazono M, Goldsmith ME, Aikou T, Bates S and Fojo T: Enhanced adenovirus transgene expression in malignant cells treated with the histone deacetylase inhibitor FR901228. Cancer Res 61: 6328-6330, 2001

44. Yoo GH, Piechocki MP, Oliver J, Lonardo F, Zumstein L, Lin HS, Kim H, Shibuya TY, Shehadeh N and Ensley JF: Enhancement of Ad-p53 therapy with docetaxel in head and neck cancer. Laryngoscope 114: 1871-1879, 2004. 